\title{
CONSIDERAÇÕES SOBRE O PAPEL DA COMUNICAÇÃO CIENTÍFICA NA EDUCAÇÃO EM QUÍMICA
}

Jane Raquel Silva de Oliveira e Salete Linhares Queiroz*

Instituto de Química de São Carlos, Universidade de São Paulo, CP 780, 13560-970 São Carlos - SP, Brasil

Recebido em 27/3/07; aceito em 27/9/07; publicado na web em 9/4/08

\begin{abstract}
CONSIDERATIONS ABOUT THE ROLE OF SCIENTIFIC COMMUNICATION IN CHEMISTRY EDUCATION. In the present work, we provide some considerations about the role of scientific communication in Chemistry Education. Such considerations may subsidize the development of communication in scientific language by Chemistry students. These considerations are based on information collected during a participatory research for the production of didactic material about scientific communication. The meetings were audio recorded and the contents of the participants' speeches were divided into categories. The category analysis supported the elaboration of the considerations.
\end{abstract}

Keywords: undergraduate education; scientific communication; participatory research.

\section{INTRODUÇÃO}

Desde a publicação, em março de 1665 , do primeiro periódico da área de Ciências Naturais, o Philosophical Transactions, a comunidade científica tem presenciado o crescimento rápido do número de publicações científicas. ${ }^{1}$ Esse aumento reflete-se, por exemplo, no número de periódicos disponíveis em bases de dados de pesquisa bibliográfica: atualmente algumas bases de dados científicas, como a SCOPUS, da Editora Elsevier, dispõem de acervos com mais de 15.000 títulos de periódicos. ${ }^{2}$ Além disso, é crescente também o número de manuscritos submetidos à publicação em cada periódico. No periódico Journal of the American Chemical Society, por exemplo, 4.474 manuscritos foram submetidos no ano de 1996 e em 2006 esse número passou para cerca de $9.471 .^{3}$

A evolução da comunicação científica está relacionada ao crescimento da comunidade científica ao longo dos séculos. Esse crescimento pode ser verificado através do número de doutores formados anualmente. Segundo Gama e Ferreira, ${ }^{4}$ os programas de pós-graduação em Química do Brasil formaram 75 doutores, entre 1983 e 1984, e 890 doutores, entre 2001 e 2003. Como conseqüência, o número de trabalhos publicados também aumentou: entre 1983 e 1984, foram publicados por esses mesmos programas de pós-graduação 477 artigos, e, entre 2001 e 2003, um total de 6.565 artigos. $^{4}$

O crescimento no número de publicações e a criação de sistemas de avaliação da literatura científica demonstram que a comunicação científica tem adquirido grande relevância não apenas para aqueles que fazem Ciência, mas também para as instituições que os abrigam. Uma das maneiras de avaliar o mérito de instituições de ensino e pesquisa é através da qualidade e da quantidade de publicações delas provenientes. No Brasil, por exemplo, o sistema de avaliação dos programas de pós-graduação criado pela Coordenação de Aperfeiçoamento de Pessoal de Nível Superior (CAPES) avalia os referidos programas com base nos seguintes indicadores: corpo docente, atividades de pesquisa, atividades de ensino, corpo discente, teses e dissertações e produção intelectual. Na área de Química, como em outras áreas da Ciência, valoriza-se mais a produção intelectual, a qual é avaliada de acordo com o total de artigos publicados em periódicos indexados. Tal indicador representa $55 \%$ da avaliação dos programas de pós-graduação, na área de Química. ${ }^{5}$

*e-mail: salete@iqsc.usp.br
Sem sombra de dúvida, no contexto atual, a capacidade de comunicação em linguagem científica é uma habilidade valiosa para aqueles que se dedicam à produção do conhecimento científico caminho esse que costuma ser trilhado por alunos de Bacharelado em Química. No entanto, o que tem se observado são os freqüentes relatos sobre a dificuldade encontrada por alunos de graduação na comunicação de seus conhecimentos. ${ }^{6} \mathrm{Na}$ tentativa de amenizar essa situação são oferecidas disciplinas, em várias universidades no exterior, que lançam mão de estratégias de ensino, usadas tanto na sala de aula como no laboratório, para aprimorar a capacidade de comunicação em linguagem científica dos alunos. ${ }^{7}$

No Brasil, até onde vai o nosso conhecimento, existem apenas 2 disciplinas que se destinam, entre outros objetivos, ao desenvolvimento de habilidades de comunicação em linguagem científica de graduandos em Química: Comunicação e Expressão em Linguagem Científica I e Comunicação e Expressão em Linguagem Científica II. Ambas são ministradas no primeiro ano do Curso de Bacharelado em Química do Instituto de Química de São Carlos, Universidade de São Paulo. ${ }^{8,9}$ Relatos presentes na literatura sobre a organização e o funcionamento de disciplinas dessa natureza, no exterior, apontam para a escassez de material didático adequado aos seus propósitos. No nosso país o quadro não é diferente: não existem relatos na literatura a respeito de publicação de materiais didáticos sobre comunicação científica específicos para estudantes da área de Química no Brasil.

Com o intuito de contribuir para a mudança desse quadro, tomamos a iniciativa de promover uma pesquisa participante,,$^{10}$ visando o desenvolvimento de um material didático sobre comunicação científica. ${ }^{11}$ Para tanto, foram consideradas as idéias e críticas de um professor universitário e de alunos de graduação e pós-graduação em Química em relação ao tema. As referidas idéias e críticas foram conhecidas a partir da transcrição dos debates por eles travados durante reuniões do grupo. Além de possibilitar a produção do material didático Comunicação e Linguagem Científica: Guia Para Estudantes de Química, ${ }^{12}$ a análise dos debates trouxe à tona algumas das concepções dos alunos e do professor sobre diversos assuntos relacionados à comunicação científica.

São numerosos os trabalhos relatados na literatura que buscam reconhecer as concepções de um determinado grupo sobre algum tema de interesse, através da análise de dados obtidos em entrevistas, transcrições de debates em grupo, questionários etc. ${ }^{13}$ Sant' Ana ${ }^{14}$ 
descreve estudo no qual foram analisadas as concepções de professores e diretores sobre questões relacionadas à inclusão escolar. Segundo a autora, a descrição das dificuldades existentes e as necessidades apontadas por esses profissionais são fontes de informações relevantes que devem ser levadas em consideração quando da decisão de novas ações no contexto "inclusão escolar". Buchweitz ${ }^{15}$ descreve um outro trabalho no qual foram analisadas as idéias de alunos concluintes de cursos de Licenciatura em Física e Ciências Biológicas com o intuito de identificar aspectos relacionados à aprendizagem significativa. Investigações a partir das falas dos sujeitos de pesquisa também são mencionadas em outros trabalhos na literatura como, por exemplo, no estudo realizado por Chamlian ${ }^{16}$ em que foram analisadas entrevistas nas quais docentes do ensino superior descreviam suas experiências inovadoras. $\mathrm{O}$ objetivo da pesquisa foi procurar subsídios para a formação do professor universitário.

Neste trabalho tivemos como objetivo discutir as concepções expressas, em relação à comunicação científica, pelos alunos de Química e pelo professor, a partir da análise dos debates citados anteriormente. Acreditamos que a análise pode subsidiar a elaboração de considerações sobre a inclusão de determinados assuntos, relacionados à comunicação científica, no rol daqueles tratados em cursos de graduação em Química no Brasil.

\section{METODOLOGIA DE PESQUISA}

\section{Pesquisa participante}

Conforme mencionamos anteriormente, o estudo aqui relatado foi realizado através de uma pesquisa participante. ${ }^{17}$ Essa é definida resumidamente como uma pesquisa na qual os próprios sujeitos a ela relacionados também estão envolvidos na construção do conhecimento e na busca de soluções para os seus problemas. ${ }^{10}$ Nessa metodologia, muda o papel do sujeito da pesquisa: ele não é só objeto estudado, é também participante ativo de todo o processo. Muda também o papel do pesquisador: ele não é mais o único dono da verdade, manipulando os sujeitos e ditando os objetivos. ${ }^{18}$

No Brasil a pesquisa participante ocupa um espaço crescente na área da Pesquisa Educacional, inclusive com apoio institucional. $\mathrm{O}$ problema de pesquisa consiste em alcançar determinados objetivos, conceber organizações, práticas educacionais e suportes materiais com características e critérios aceitos pelos grupos interessados. ${ }^{19}$ Araújo, ${ }^{20}$ em trabalho publicado na revista Educação e Pesquisa, relatou um estudo baseado na metodologia de pesquisa participante que teve como objetivo compreender como as vivências escolares de jovens, cujo cotidiano é marcado pela violência, reorientam atitudes dos alunos entre si, e desses em relação aos professores e outros agentes escolares. Outro caso de aplicação da pesquisa participante na área de Educação é o trabalho desenvolvido por Fonseca, ${ }^{21}$ no qual a metodologia foi utilizada para o desenvolvimento de um material didático de Educação em Saúde - Cartilha Educativa de Atenção ao Bebê Prematuro - através da ação conjunta de pesquisadores, enfermeiras e mães de bebês prematuros.

Dessa forma, delinear o percurso metodológico do presente trabalho, tendo por base a pesquisa participante, mostrou-se conveniente uma vez que o objetivo do nosso trabalho foi a elaboração de um material didático sobre comunicação em linguagem científica e acreditamos que, para atingir tal objetivo, seria importante a participação dos interessados durante todo o processo a ser adotado, a fim de que fosse possível conhecer suas realidades e obter suas impressões sobre o material.

\section{Metodologia de coleta e análise de dados}

Neste estudo foi seguida a seqüência metodológica sugerida por Le Boterf, ${ }^{17}$ para a realização de pesquisas participantes, dividida em 4 fases: $1^{\text {a }}$ ) Montagem institucional e metodológica. É a fase de elaboração das estratégias adotadas, definição dos sujeitos da pesquisa e da área de atuação; $2^{\mathrm{a}}$ ) Estudo preliminar e provisório. Busca da percepção prévia dos indivíduos relacionados à pesquisa; $3^{\text {a }}$ ) Análise crítica dos problemas considerados prioritários. Fase de discussões livres dos sujeitos participantes da pesquisa; $4^{\mathrm{a}}$ ) Programação e execução de um plano de ação (incluindo ações educativas). Fase de definição da melhor estratégia para atingir os objetivos da pesquisa, de maneira que responda aos questionamentos levantados nas discussões em grupo.

A primeira fase do presente trabalho, montagem institucional e metodológica, consistiu na seleção dos sujeitos envolvidos na pesquisa. Além do pesquisador (PQ), responsável pela organização e desenvolvimento dos debates, foram convidados a participar da pesquisa os seguintes sujeitos: 1 professor do ensino superior de Química (PR), 2 alunos de pós-graduação em Química (1 mestrando, $\mathrm{AP}_{1}$, e 1 doutorando, $\mathrm{AP}_{2}$ ) e 4 alunos do curso de graduação em Química (2 matriculados no segundo ano, $\mathrm{AG}_{1}$ e $\mathrm{AG}_{2}$, e 2 alunos de iniciação científica, matriculados no último ano, $\mathrm{AI}_{1}$ e $\mathrm{AI}_{2}$ ).

Os critérios adotados para seleção dos participantes basearam-se no envolvimento de cada um com a comunicação científica em diferentes estágios, bem como no fato de todos estarem ligados à área de Química. Esperava-se que cada participante apresentasse concepções e experiências distintas relacionadas à comunicação científica: educandos, em diferentes estágios de formação acadêmica, e educador contribuiriam ativamente no processo da pesquisa participante.

A segunda fase da pesquisa participante consistiu de um estudo preliminar provisório, no qual buscamos compreender como os estudantes de Química interpretam os problemas relacionados à comunicação científica. Para atingir tal objetivo, o pesquisador acompanhou aulas da disciplina Comunicação e Expressão em Linguagem Científica I, anteriormente citada. Assim, foi possível observar as dificuldades dos estudantes e recolher suas impressões sobre a comunicação científica. Tais informações foram utilizadas como ponto de partida para as discussões em grupo, realizadas na fase subseqüiente da pesquisa.

Após seleção e convite dos sujeitos de pesquisa, foi levada a cabo a terceira fase da pesquisa: análise crítica dos problemas considerados prioritários. Foi realizada uma reunião inicial para apresentação da proposta de estudo ao grupo e entrega do Termo de Consentimento Informado, no qual foram esclarecidos os objetivos do estudo e as normas éticas a partir das quais a pesquisa seria regida. Foi ainda estabelecida a programação das reuniões. Nessa fase da pesquisa foram discutidos os problemas dos alunos e dos professores (no contexto da comunicação científica), estabelecidos os objetivos do material didático que seria elaborado, bem como os tópicos que seriam nele incluídos, sua forma de organização e apresentação. Foram realizadas 4 reuniões e, em uma delas, os debates ocorreram em grupos separados: no primeiro grupo estiveram presentes os alunos de graduação e no segundo grupo, os alunos de pós-graduação e o professor. $\mathrm{O}$ objetivo das reuniões em grupos menores foi deixar os participantes mais livres de influências externas para expressarem suas opiniões e idéias. Assim, os alunos de graduação, por exemplo, se sentiram mais à vontade sem a presença do professor e de outros alunos "mais conhecedores" do tema. Os outros participantes, da mesma forma, expressaram livremente suas idéias e contribuições à pesquisa. Convém ressaltar que as discussões realizadas na fase de análise crítica dos problemas considerados prioritários, embora originalmente direcionadas à produção do material didático, 
forneceram também a maior parte dos dados para a análise das concepções do professor e dos alunos de Química sobre comunicação científica, apresentadas neste artigo.

A última fase da pesquisa foi a realização da programação $e$ execução de um plano de ação, a qual incluiu a produção e a validação do material didático. O desenvolvimento de cada tópico do material didático, seus conteúdos, sequiência dos tópicos, subdivisões, linguagem utilizada etc foi conduzido a partir de dados obtidos na literatura e, principalmente, das idéias, sugestões e críticas fornecidas pelos sujeitos da pesquisa no decorrer de mais 4 reuniões de grupo. À medida que partes do material foram sendo elaboradas, foram entregues previamente aos sujeitos para sua avaliação e discussão na reunião seguinte.

Todas as reuniões foram gravadas em áudio e as falas dos sujeitos da pesquisa transcritas. A partir da análise das transcrições, as concepções dos alunos e do professor foram reunidas em categorias de temas discutidos sobre a comunicação científica.

Cabe destacar que a descrição detalhada sobre o processo de elaboração e validação do referido material didático, bem como sobre os reflexos da pesquisa participante na sua elaboração, não serão discutidos neste artigo, mas estão disponíveis na dissertação de mestrado de uma das autoras deste trabalho ${ }^{11}$ e em artigo publicado na Revista Electrónica de Enseñanza de las Ciencias. ${ }^{22}$

\section{RESULTADOS E DISCUSSÃO}

Os sujeitos foram convidados a tomar parte em 8 reuniões durante o processo de realização da pesquisa. Dadas as características da pesquisa participante, na qual os sujeitos colaboram voluntariamente, nem sempre foi possível ter presente, em cada uma delas, todos os envolvidos no processo. No entanto, nas raras ocasiões em que alguns dos sujeitos não participaram das reuniões, manifestaram, posteriormente, por escrito, as suas idéias a respeito dos tópicos discutidos na ocasião. A partir da análise das suas manifestações orais e escritas, identificamos e categorizamos os temas mais recorrentes. As principais categorias de discussão sobre a comunicação científica identificadas foram: A Importância da Comunicação Científica; O Relatório de Laboratório; Apresentações Orais e Escrita Científica; Ética em Comunicação Científica; A Evolução da Ciência e Sua Especialização. A Tabela 1 apresenta o número de vezes que os sujeitos de pesquisa se manifestaram sobre assuntos a elas vinculados.

Os dados presentes na Tabela 1 indicam que, para os alunos de graduação, questões relacionadas às apresentações orais e trabalhos escritos (12 citações) mereceram particular atenção, sendo mais enfatizadas por eles que pelos demais sujeitos. Isto se deve, provavelmente, ao fato dos alunos estarem realizando tarefas no curso de graduação que exigem habilidades de comunicação em

Tabela 1. Categorias de temas relacionados à comunicação científica e número de citações entre os sujeitos de pesquisa

\begin{tabular}{lccc}
\hline Categorias & $\begin{array}{c}\text { Alunos de } \\
\text { graduação }\end{array}$ & $\begin{array}{c}\text { Alunos de } \\
\text { pós-graduação }\end{array}$ & Professor \\
\hline A Importância da & 1 & 5 & 5 \\
$\begin{array}{l}\text { Comunicação Científica } \\
\text { O Relatório de Laboratório }\end{array}$ & 6 & 3 & 7 \\
$\begin{array}{l}\text { Apresentações Orais } \\
\text { e Escrita Científica }\end{array}$ & 12 & 2 & 5 \\
$\begin{array}{l}\text { Etica em Comunicação } \\
\text { Científica }\end{array}$ & 2 & 4 & 7 \\
$\begin{array}{l}\text { A Evolução da Ciência } \\
\text { e sua Especialização }\end{array}$ & - & 1 & 2 \\
\hline
\end{tabular}

linguagem científica, que se apresentam como desafiadoras. Em contrapartida, os alunos pouco se manifestaram sobre categorias que estão mais estreitamente relacionadas à vida profissional do pesquisador, tais como a importância da comunicação científica (1 citação), ética em comunicação científica (2 citações) e a evolução da ciência e sua especialização (nenhuma citação). Provavelmente porque tópicos dessa natureza fazem parte das preocupações do dia-a-dia de alunos de pós-graduação e do professor e foram mais discutidos por eles: a importância da comunicação científica (5 citações por alunos de pós-graduação e 5 pelo professor), ética em comunicação científica (4 citações por alunos de pósgraduação e 7 pelo professor). Questões relacionadas à evolução da ciência e sua especialização não foram alvo de muitas discussões, apenas os alunos de pós-graduação e o professor trataram do assunto (1 citação por alunos de pós-graduação e 2 pelo professor).

Aspectos relacionados à categoria relatório de laboratório foram discutidos com frequiência por todos os sujeitos, sugerindo a sua importância no cotidiano de cada um deles. No entanto, não é surpreendente que os alunos de graduação e o professor tenham apresentado maior interesse pelo tema: para os graduandos, o relatório de laboratório está extremamente presente em suas atividades acadêmicas e, portanto, esse fato se refletiu no número de citações sobre o tema (6 citações). O relatório de laboratório também faz parte do cotidiano do professor (7 citações), que necessita orientar os alunos sobre a sua confecção e estabelecer critérios para a sua correção.

As principais discussões geradas sobre assuntos relacionados a cada uma das categorias identificadas no estudo são apresentadas a seguir. $\mathrm{O}$ estabelecimento de relações entre as referidas discussões e algumas ponderações presentes na literatura sobre questões concernentes ao desenvolvimento de habilidade de comunicação em linguagem científica de estudantes das áreas de Ciências Exatas permitiu a tecedura de considerações sobre a necessidade de inclusão de determinados tópicos, relacionados à comunicação científica, no rol daqueles tratados em cursos de graduação em Química no Brasil.

\section{A importância da comunicação científica}

As discussões sobre a importância da comunicação científica estiveram direcionadas, principalmente, para os alunos de graduação. Ou seja, nessa categoria o foco da discussão foi a importância da comunicação científica para os alunos de graduação em Química. Porém, apesar de todos os sujeitos de pesquisa terem se pronunciado sobre a importância das habilidades de comunicação em linguagem científica para os graduandos, suas concepções não foram uniformes. Os alunos de graduação se posicionam sobre o tema, como ilustrado a seguir.

$\left.\mathbf{A G}_{\mathbf{2}}\right)$ "De fundamental importância, não só para o graduando de Química quanto para outros graduandos de cursos de Ciências, a comunicação científica é a única forma de fazer com que as pessoas se comuniquem, a entender e explicar modelos e conceitos, tirar dúvidas, relatar idéias, fazer monografias, apresentações $e$ até mesmo a responder questões de prova”.

O professor, por outro lado, enfatiza a importância da comunicação científica a partir de uma visão de benefícios em longo prazo, sobretudo na vida profissional.

(PR) "Qualquer aluno de Química deve dominar a linguagem científica sobre sua área, pois esta é sua moeda de sucesso. Só através da transmissão de seus conhecimentos e de suas idéias é que o aluno, futuro profissional de Química, poderá galgar sucesso”. 
E por fim, os alunos de pós-graduação, embora também direcionem a comunicação científica para o futuro profissional do químico, ressaltam ainda sua importância tanto no universo acadêmico quanto em qualquer outra área de atuação profissional.

$\left(\mathbf{A P}_{2}\right)$ "Ela é fundamental não só para os graduando que se direcionam para a vida acadêmica, mas também para os indivíduos que exercerão qualquer atividade diária onde seja necessária a expressão por meios de relatórios, projetos, memorandos etc.; ou a comunicação direta com pessoas, palestras, consultorias etc.”.

Embora a importância da comunicação científica para o profissional da Química seja um tema que, por vezes, é abordado em disciplinas clássicas da grade curricular dos cursos de graduação da área no nosso país, essa abordagem, usualmente, é feita de maneira informal por parte dos professores. Em contrapartida, nos últimos anos, pesquisadores da área de Educação em Ciências têm chamado a atenção para a necessidade da implementação de ações direcionadas para a conscientização dos estudantes sobre a importância da comunicação científica e também sobre as diversas formas como esta comunicação se dá. O trabalho de Zanon e colaboradores, ${ }^{23}$ por exemplo, relata a aplicação de uma estratégia de ensino, pautada na leitura, por parte de alunos de graduação em Química, do capítulo Visita de um Antropólogo ao Laboratório, presente no livro A Vida de Laboratório, de Bruno Latour e Steve Woolgar. ${ }^{24}$ A realização da atividade visava fomentar discussões sobre o papel da linguagem científica no cotidiano dos profissionais da área e, segundo as autoras, "após a leitura do texto e no final do semestre notamos deslocamentos nas concepções iniciais de todos os alunos, principalmente no que se refere à importância da construção de artigos científicos".

Por sua vez, a apresentação aos estudantes das diversas formas como a Ciência é divulgada favorece o entendimento sobre as características inerentes da linguagem científica, da qual eles precisam se apropriar, e a desmistificação a respeito da construção do conhecimento científico. ${ }^{25-27}$ Fortner, ${ }^{28}$ por exemplo, se vale de atividades pautadas na aprendizagem colaborativa ${ }^{29}$ para introduzir aspectos que diferenciam a literatura primária da literatura secundária em uma disciplina de comunicação científica, ministrada para estudantes de Ciências do Ambiente.

\section{$O$ relatório de laboratório}

Um tema bastante discutido entre os participantes foi o relatório de laboratório. Algumas das suas características, assim como o seu processo de confecção, foram trazidas à baila. As falas dos alunos de graduação deixaram transparecer que nas disciplinas práticas de Química, no primeiro semestre, nem sempre ocorre a produção de um relatório no formato que é característico no restante do curso (usualmente dividido nas seções Introdução, Objetivos, Materiais e Métodos, Resultados e Discussão, Conclusões e Bibliografia). Na etapa inicial é comum que o preenchimento de fichas, contendo questionamentos sobre os procedimentos adotados e resultados obtidos durante as aulas, substitua essa produção, conforme relata um dos graduandos.

$\left(\boldsymbol{A} \boldsymbol{G}_{1}\right)$ "No começo, assim, para a gente preparar os relatórios eles (os professores) tentam facilitar um pouco. Eles dão um caderno e a gente só vai preenchendo. É, na verdade, é uma ficha. Então, quer dizer, em parte tirou do aluno ter que correr atrás, digitar os relatórios, preparar. A gente só preenche dados, não monta a estrutura, pois ela já está pronta”.
Por outro lado, os alunos de pós-graduação contam que quando elaboram seus próprios relatórios, esses, de um modo geral, guardam muitas semelhanças com relatórios já produzidos por outros membros do laboratório de pesquisa onde atuam, conforme explicitado a seguir.

$\left(\mathbf{A P}_{2}\right)$ "Muitas vezes a gente faz um trabalho e vai se guiando por outros. Eu peguei alguns trabalhos e tinha alguns relatórios que tinham algumas técnicas que a gente estava aprendendo. Uma série de pessoas fez idêntico, inclusive nos títulos! Então ocorre uma má impressão nisso, parece que você não está evoluindo muito... Era gritante, era tudo muito parecido! E acaba a Introdução sendo muito parecido numa tese de doutorado ou que seja numa tese de mestrado... tudo a mesma coisa! Você acaba olhando o anterior. 'Olha lá como fulano fez e faz assim'. Eu achei que ficou feio."

Questionamentos importantes podem ser levantados a partir das colocações dos estudantes. O primeiro diz respeito aos benefícios trazidos (ou não) pelo preenchimento de fichas ao invés da solicitação de um relatório mais formal e completo aos alunos ingressantes nos cursos de Ciências Exatas; o segundo relaciona-se à "paráfrase", por vezes realizada pelos alunos de pós-graduação, dos trabalhos escritos pelos colegas do laboratório de pesquisa, na elaboração de seus próprios relatórios de pesquisa.

Percebe-se assim, de acordo com o que foi relatado, que existe um desconforto e pouca clareza com relação à maneira correta de proceder, tanto por parte dos alunos de graduação quanto por parte dos alunos de pós-graduação, quanto à confecção de relatórios. As colocações do professor sobre o assunto, apresentadas a seguir, evocam as raízes do problema.

(PR) "Eu digo o que acontece, e diria que aqui deve acontecer isso também: é que ninguém nos ensinou a fazer isso, não é? Um laboratório faz assim, os outros, já são outras pessoas que fazem diferente. Ninguém diz "leia aqui como fazer um relatório"”.

(PR) "Relatórios - um problema sério na vida do aluno. Vários aspectos nos levam a não ensinar bem o aluno a escrever um relatório. Primeiro porque nós aprendemos aos trancos e barrancos, ninguém nos ensinou. Então, cada uma faz um relatório como acha que deve ser feito. [...] (O aluno) copia do colega, mas esse colega copiou do outro colega que foi ensinado por um professor mal preparado para isso também, no qual eu me incluo também”.

A sua preocupação sobre a ausência de orientações claras, por parte de muitos docentes, sobre os principais fundamentos que os graduandos precisam conhecer para alcançar sucesso na produção dos seus relatórios de laboratório é compartilhada com outros professores da área de Ciências Exatas e com pesquisadores da área de Educação em Ciências. ${ }^{30}$ Muitos deles chamam atenção para o fato da produção de relatórios de laboratório, corriqueira nos cursos de Química, se apresentar como uma excelente oportunidade para o ensino aos graduandos de algumas características inerentes à linguagem científica. ${ }^{31} \mathrm{O}$ trabalho de Luz Jr. e colaboradores, ${ }^{32}$ recentemente publicado nesta revista, assim como o de Tilstra, ${ }^{33}$ publicado no Journal of Chemical Education, harmonizam-se com tal idéia: no primeiro, os relatórios são corrigidos de acordo com roteiro previamente estabelecido (sendo destacados os erros de conteúdo e de forma de apresentação cometidos) e, posteriormente, devolvidos aos alunos para uma apreciação crítica. Tilstra, ${ }^{33}$ por sua vez, relata a aplicação de uma série de atividades relacionadas a técnicas de escrita em linguagem científica, caracterizadas por mudanças gradativas 
na forma de solicitação da apresentação dos relatórios produzidos pelos estudantes durante o período letivo. O grau de exigência a respeito da confecção dos relatórios é crescente no período.

Cabe ainda destacar que, segundo a percepção do professor (sujeito da pesquisa), o fato de tanto ele como outros colegas não fornecerem orientação precisa aos estudantes, com relação à confecção de relatórios, é fruto de uma formação docente que, em geral, não contemplou tais aspectos. Ou seja, não são apenas os alunos que "copiam" os relatórios dos colegas: os professores, por não terem recebido, no seu período de formação, orientações sobre aspectos relacionados à redação de documentos científicos, como os relatórios, também "copiam" os modelos que lhes foram repassados quando eram alunos. No tocante à formação dos professores do ensino superior, Arroio e colaboradores ${ }^{34}$ ressaltam que os professores universitários, em geral, utilizam suas próprias experiências na elaboração das suas práticas pedagógicas. Além disso, os autores também reconhecem que, diante desse despreparo, alguns docentes sentem-se, muitas vezes, inseguros em relação ao melhor caminho a ser adotado em determinadas situações. Ou seja, conforme comentado anteriormente pelo professor, por terem aprendido "aos trancos e barrancos", "cada um faz um relatório como acha que deve ser feito".

\section{Apresentações orais e escrita científica}

Aspectos relacionados à apresentação de conteúdos científicos, tanto na forma oral como na forma escrita, foram discutidos pelos sujeitos de pesquisa. A seguir é apresentado o trecho de um diálogo entre o pesquisador e os alunos de graduação, no qual as dificuldades dos estudantes, em relação à prática de apresentações orais, são debatidas.

(AG $\left.\mathbf{A}_{1}\right)$ "A gente tinha apresentações de seminários, a gente resolvia o caso e depois apresentava. Só que no grupo éramos em 4 ou em 5, aí só 1 apresentava. Só 1 passava pela experiência...”.

(PQ) "Mas, no começo, o que vocês lembram?O que era mais difícil? Falar ou preparar os trabalhos escritos?”.

(AI) "Eu acho que é falar, porque você fica assim naquela tensão, de... De repente te dá um branco no meio da apresentação, ou fica imaginando o que o professor está pensando".

(PQ) "Porque de qualquer forma você está sendo avaliado ali. Então, o fato de você estar sendo avaliado já gera uma tensão”.

(AG $\left.\mathbf{A}_{1}\right)$ "Eu não sei, eu acho que só treino mesmo. E a gente conseguir achar uma maneira de, por exemplo, mais pessoas apresentarem. É como a gente falou o professor vê, tanto da primeira e da segunda vez, mas o grupo tem 4 ou 5 elementos, mas só 2 apresentam, os outros ficaram sem passar por essa experiência. Todos treinaram, mas...”.

(AI) "Talvez na graduação se tivesse algumas matérias em que isso pudesse ser encaixado poderia até ser facilitado a comunicação porque exigiria mais da parte do aluno. O aluno fica muito na escrita e perde a parte da linguagem, da fala".

Observa-se que, embora os alunos reconheçam a tensão gerada diante da perspectiva de fazer uma exposição oral sobre um determinado assunto, gostariam que fossem acrescentadas às disciplinas mais atividades dessa natureza. No diálogo a seguir, algumas das suas dificuldades nos momentos de apresentação oral são discutidas.
$\left(\mathbf{A I}_{2}\right)$ "Os meninos da minha turma reclamam muito é sobre postura, porque chega lá na frente eles não sabem como ficar. E aí fica meio desajeitado e aquilo acaba atrapalhando a apresentação. E aí não sabe se coloca a mão na cadeira, na frente, ou se fica na frente da mesa ou atrás da mesa, e às vezes ficam com aquele "negocinho" (ponteira do laser) na mão, mesmo às vezes não estando usando. E vai para um lado e para o outro...[...]

( $\left.\mathbf{A G}_{\mathbf{1}}\right)$ "Às vezes as pessoas fazem uma apresentação e colocam slides muito pesados que "jogam" muita informação ou outro muito rápido. Você está lendo lá e quando ainda você não terminou de ler, a pessoa pára e começa a falar, e parece que você não prestou a atenção".

$\left.\mathbf{A I}_{2}\right)$ "A professora, falou lá, da apresentação "karaokê": às vezes a pessoa coloca tudo o que vai falar no slide...”.

Se, por um lado, os alunos de graduação relataram ser a expressão oral a maior dificuldade que enfrentam em relação à comunicação científica, opiniões divergentes foram emitidas pelo professor e pelos alunos de pós-graduação. Segundo eles, escrever adequadamente em linguagem científica é mais difícil que apresentar os conteúdos científicos na forma oral, conforme ilustra o diálogo a seguir.

(AP1) "Antes da sua chegada, eu estava discutindo que falar não é difícil, a pessoa se preparando para aquele momento antes. Já escrever não, precisa de uma maior bagagem de conhecimento, que ela vai ganhando com o tempo de... de conhecimento diário".

(PR) "O negócio que eu vejo, é que para escrever, você está registrando, você precisa de uma pouco mais de precisão, então fica mais difícil. Quando você vai falar você pode explicar o que você está querendo dizer. Agora, quando você vai escrever, a priori, é para você mesmo. Você não tem um interlocutor para te questionar, o que você quer dizer, daí a dificuldade. Muitas vezes quando a gente vai corrigir uma prova, que o indivíduo, por falta da precisão, escreve coisas que não são inteligíveis, daí ele diz "Mas está claro!". Está claro pra ele, mas não para mim".

A divergência de opinião, entre os alunos de graduação e os demais sujeitos, sobre o grau de dificuldade na produção de trabalhos escritos ou orais na linguagem da Ciência, remeteu-os à discussão acerca da precisão na redação de textos científicos.

$\left(\mathbf{A P}_{1}\right)$ "E não é só um problema da graduação. A gente estava discutindo a dificuldade, por exemplo, de reproduzir um experimento em um artigo. E aí cai justamente nisso, a pessoa deixa passar alguma coisa...”.

(PR) "Não está claro! Aí "tal experimento pode ser feito em certas circunstâncias". Ele pode ser feito ou ele deve ser feito? Porque são coisas diferentes, se você falar que deve ser feito é que se não fizer assim vai dar errado. Deve ser feito na ausência de luz, é diferente de pode ser feito na ausência de luz.".

As manifestações dos sujeitos evidenciam o lugar de destaque que o domínio da comunicação oral e escrita, em linguagem científica, ocupa na vida de cada um deles. É, portanto, surpreendente que sejam ainda poucas as iniciativas relatadas na literatura, pelo menos no nosso país, que tratam da elaboração de atividades didáticas no ensino superior de Química, visando oferecer aos alunos ferramentas que os levem a alcançar esse domínio. Assim, 2 arti- 
gos publicados recentemente nesta revista, que se remetem à questão, são dignos de nota: o trabalho de Santos e colaboradores ${ }^{25}$ trata de atividades pautadas no uso da literatura primária em uma disciplina de Físico-Química. Segundo os autores, as atividades, que abarcaram a leitura de artigos científicos e posterior redação de resumos sobre o conteúdo desses artigos, serviram tanto para reforçar a aprendizagem em Química, quanto para desenvolver a capacidade de expressão em linguagem escrita e de localização de referências primárias e secundárias. No trabalho de Sá e colaboradore $^{35}$ o desenvolvimento da habilidade de comunicação oral dos alunos é buscado através da aplicação da estratégia de ensino conhecida como estudo de casos. Nessa proposta os estudantes receberam um caso investigativo de caráter sócio-científico e realizaram pesquisas em fontes bibliográficas diversas que os capacitaram a solucioná-lo. Uma vez cumprida essa etapa inicial, as resoluções dos casos foram apresentadas oralmente pelos estudantes para os companheiros de turma e para o docente responsável pela disciplina na qual a atividade foi promovida. Segundo as autoras, além do aprimoramento das habilidades de comunicação oral dos estudantes, as atividades também favoreceram o aprimoramento de habilidades como a realização de trabalho em grupo, tomada de decisões, criatividade, senso crítico etc.

Contrastando com a escassez de trabalhos na literatura nacional, verificamos, através de levantamento bibliográfico, ${ }^{7}$ que são numerosos os artigos sobre o assunto em questão na literatura internacional. Em uma revisão feita no periódico Journal of Chemical Education, no período de 1994 a 2004, foram localizados 29 artigos que relatam experiências relacionadas ao desenvolvimento da expressão oral e escrita em disciplinas de Química, as quais se subdividem em 2 tipos: as disciplinas voltadas especificamente para o desenvolvimento de tais habilidades ( $41 \%$ dos artigos pesquisados) e, as disciplinas direcionadas ao ensino de Química, mas que trazem em seu bojo a preocupação com o desenvolvimento de tais habilidades (59\% dos artigos pesquisados). Nas disciplinas específicas o tempo disponível para a realização de atividades que visam o aprimoramento das habilidades acima descritas é sempre maior, quando comparado às disciplinas direcionadas para o ensino de Química. Em contrapartida, essas últimas permitem uma contextualização das atividades com o conteúdo das disciplinas, que é entendida como extremamente estimulante para os estudantes e que tem rendido bons frutos.

As dificuldades encontradas pelos alunos (sujeitos da pesquisa) em relação às apresentações orais, evidenciadas nos diálogos mantidos com o pesquisador, são também relatadas em outros trabalhos na literatura. Meyer, ${ }^{36}$ por exemplo, demonstrou através de testes quantitativos que a exposição oral em público gera alto grau de ansiedade nos estudantes e que através de atividades práticas de apresentações de seminários é possível desenvolver as suas habilidades de expressão oral, reduzindo assim o grau de ansiedade diante do público. Grace e Gilsdorf ${ }^{37}$ também relataram uma estratégia desenvolvida em sala de aula visando desenvolver tais habilidades: a realização de várias apresentações orais pelos alunos, partindo gradativamente de temas mais simples e com menor tempo de exposição para apresentações com temas mais complexos e com maior duração. Essa é, portanto, uma entre várias estratégias que podem ser utilizadas com o intuito de proporcionar ao aluno mais "treino" em apresentações orais - como foi sugerido por um aluno, sujeito da pesquisa.

\section{Ética na comunicação científica}

Questões relacionadas à ética também foram discutidas entre os sujeitos da pesquisa. Os alunos de pós-graduação e o professor fizeram afirmações mais contundentes sobre o assunto e tocaram em pontos nevrálgicos relacionados à maneira como a Ciência vem sendo produzida e divulgada. Assim, de acordo com suas concepções, percebem a importância da divulgação dos seus trabalhos de pesquisa, mas reconhecem que alguns limites éticos vêm sendo constantemente transgredidos na comunidade científica.

No trecho apresentado a seguir são colocados 2 aspectos que costumam ser alvo de atenção em debates que tratam da ética em Ciência: ${ }^{38}$ a divulgação para o público de informações dúbias ou enganosas por parte dos responsáveis por uma determinada pesquisa e a autoria em trabalhos científicos.

(PR) "Porque, de fato, o que a gente vê aí no ambiente cientifico é que aqueles que fazem marketing são tidos com os grandes, aquele que só trabalha... Você vê... tem gente que é garganta que só fala o que faz, mas na hora que você aperta para saber o que faz, você vê que não faz nada, é só fala. É o marketing”.

$\left(\mathbf{A P}_{2}\right)$ "Tem que vê se... Tem um lado ruim disso aí. Porque tem que aprender a vender o peixe dele. Ele precisa, não é?’”.

(PR) "Precisa! Mas também você não pode ser só antiético, o que muita gente é”.

(PR) “Autores, também é outro problema. Tem orientador, por exemplo, que coloca egoisticamente o nome dele primeiro (no artigo) e depois o nome do resto. Tem gente que já coloca o nome dele no final. E aí vai mais a parte de ética de que qualquer outra coisa".

Os questionamentos éticos relacionados à autoria em trabalhos científicos, abordados pelos sujeitos, também são encontrados no artigo de Cavalcanti e Rode. ${ }^{39}$ Os pesquisadores, além de alertarem para a necessidade de consciência ética quando da determinação dos autores de um trabalho submetido à publicação, relatam alguns fatos considerados antiéticos, tais como a redundância de publicações ou inclusão de autores que não participaram efetivamente das pesquisas.

A idéia de que a quantidade de publicações científicas influencia diretamente a vida profissional do pesquisador tem sido amplamente divulgada nos últimos anos. Rosenfeldt e colaboradores ${ }^{40}$ apontam, por exemplo, que um dos motivos que leva os pesquisadores à busca por um número cada vez maior de publicações é, além da divulgação do conhecimento, a obtenção de reconhecimento da comunidade científica. Frente à grande pressão das agências de fomento e dos órgãos governamentais para que os cientistas publiquem cada vez mais, muitos pesquisadores têm enfrentado a busca constante por quantidade de publicação. ${ }^{41}$ De fato, no Brasil, segundo Hermes-Lima, ${ }^{42}$ mesmo com gastos elevados e investimentos baixos, o número de publicação tem crescido continuamente. Dessa forma, consegue-se produzir Ciência, mas com alto custo humano: em geral, trabalha-se sob pressão, com grande desgaste do pesquisador.

Diante desses fatos, é compreensível que o tratamento do tema Ética na Comunicação Científica tenha provocado debates acaloradas entre os participantes da pesquisa. Como também é compreensível que um consenso a respeito da inclusão da discussão de temas dessa natureza em disciplinas dos cursos de graduação em Química venha se instaurando nos últimos anos, notadamente no exterior. ${ }^{43}$

A abordagem de questões relacionadas à ética em Ciência tem sido observada em disciplinas dos cursos de graduação em Química nas quais são aplicadas atividades que favorecem discussões sobre esse tema. Dentre as estratégias utilizadas estão a leitura e discussão de textos que tratam de aspectos relacionados à publicação como plágio, indução ou falsificação de dados, conflitos de interesse, atribuição de créditos etc. ${ }^{43}$ A estratégia de aplicação de 
estudos de casos envolvendo situações de conflitos éticos, na qual os alunos, em grupo, discutem e decidem sobre a conduta mais adequada a ser estabelecida diante do problema proposto também tem sido adotada. ${ }^{44}$

\section{A evolução da ciência e sua especialização}

A temática evolução da ciência e sua especialização não foi alvo de muitos debates. Foram levantados questionamentos sobre o papel do pesquisador diante do grande número de informações publicadas na literatura científica atualmente e da conseqüente necessidade de especialização por parte dos mesmos em áreas cada vez mais específicas. No trecho a seguir algumas ponderações a esse respeito são feitas pelos participantes da pesquisa.

(PR) "E nós mesmos, não só os jovens, temos que ler tanta coisa que você lê apenas os Abstracts de uma coisa. Você não lê o todo para poder interpretar. Não é só o jovem que passa por isso, não”.

(PQ) "É uma tendência, da especialização... é você saber cada vez mais de cada vez menos".

(PR) "Aí você realmente fica com dificuldade. Você pega a Ciência, ela está tão ampla também que às vezes você vai a algum seminário e você não entende nada. Às vezes o cara está falando de uma coisa tão avançada que já fugiu da realidade e você não entende nada do que se está falando. Aqueles de 20 anos atrás, quando você ia a um seminário a coisa era restrita, os assuntos eram limitados".

Os diálogos ocorridos sobre o tema serviram para corroborar o fato de que a especialização foi a maneira encontrada pela comunidade científica para lidar com a quantidade cada vez maior de informações disponibilizadas no decorrer dos anos. De fato, os cientistas foram, ao longo dos tempos, cada vez mais, se aprofundando em uma área da Ciência e, mais adiante, em assuntos ou linhas de pesquisa dentro de uma mesma área. Essa especialização do conhecimento pode ser observada de forma mais clara nas transformações ocorridas nos títulos dos periódicos. Embora ainda existam revistas que publicam sobre assuntos diversos relacionados à área da Química, como a revista Química Nova, hoje temos periódicos que se destinam à publicação de artigos sobre assuntos cada vez mais específicos, como a revista Nitric Oxide, que divulga trabalhos de pesquisas especificamente relacionadas ao óxido nítrico. A mesma tendência é observada na organização das reuniões científicas. Existem encontros mais abrangentes como a Reunião da Sociedade Brasileira para o Progresso da Ciência (SBPC), ou de uma única área da ciência como a Reunião Anual da Sociedade Brasileira de Química (SBQ), ou ainda de subáreas como o Congresso Brasileiro de Catálise (CBCat).

\section{CONSIDERAÇÕES FINAIS}

As discussões apresentadas neste artigo apontaram para as diferentes visões dos sujeitos sobre os temas abordados. Os alunos de graduação percebem a importância da comunicação científica, sobretudo no contexto da realização das suas atividades acadêmicas, enquanto os alunos de pós-graduação e o professor visualizam sua importância para a vida profissional. As concepções dos sujeitos sobre o relatório de laboratório também são bastante divergentes: os alunos de graduação questionam o fato de, nas primeiras aulas de laboratório das quais tomam parte, preencherem fichas ao invés de produzirem um relatório completo, no formato tradicional; os alunos de pós-graduação relatam que os relatórios que escrevem, em geral, são muito semelhantes a outros já elaborados por "veteranos" do laboratório; e o professor questiona se o modelo de relatório que ensina aos alunos é o mais adequado.

Questões concernentes às apresentações orais e à escrita científica também foram encaradas de maneiras distintas pelos participantes: os alunos de graduação falam da grande dificuldade que enfrentam na realização de apresentações orais; alunos de pós-graduação e o professor descrevem a tarefa de produzir documentos escritos como sendo mais árdua que a realização de apresentações orais. Em relação à ética em comunicação, todos reconhecem a importância da publicação para o pesquisador, embora questionem alguns aspectos relacionados à forma como a ciência é divulgada. Por fim, o professor e alunos de pós-graduação reconhecem suas limitações de estudo frente à evolução da ciência e à sua especialização.

É importante frisar que as concepções sobre a comunicação científica reunidas neste estudo, colhidas em um contexto em que apenas um único professor e poucos alunos foram escutados, não podem ser generalizadas. Ainda assim, o estudo permitiu que algumas importantes considerações fossem tecidas. Considerações essas, apresentadas a seguir, que podem subsidiar a elaboração de propostas de ensino que tragam em seu bojo a preocupação mais efetiva com o desenvolvimento de habilidades de comunicação em linguagem científica de alunos de graduação em Química: é importante o oferecimento de atividades que aprimorem a habilidade de comunicação em linguagem científica dos alunos e possibilitem aos mesmos a compreensão, desde os primeiros anos da graduação, do papel relevante que a comunicação científica ocupa na formação do profissional da área de Química. Essa compreensão pode servir de estímulo para uma atuação mais responsável durante a realização de estágios de iniciação científica e durante a participação em eventos científicos, por exemplo. Atividades com o caráter referido no tópico anterior podem ser oferecidas tanto em disciplinas especificamente direcionadas para a discussão de questões relacionadas à comunicação científica, como nas diversas disciplinas da área de Química, que permeiam o curso. A comunicação em linguagem científica, o reconhecimento das diversas formas como a Ciência é divulgada, das características inerentes aos vários tipos de documentos produzidos pela comunidade científica, assim como a localização de tais documentos, são parte de um cabedal de conhecimentos e de habilidades que necessita ser tratado de forma enfática nos cursos de Química, e cujo entendimento pode ser facilitado a partir da realização de exercícios de caráter prático e de discussões em sala de aula. Atividades nos cursos de graduação que incluam, entre outras, a apresentação oral, a produção de painéis e de relatórios a respeito de assuntos relacionados a tópicos ministrados nas disciplinas podem ser extremamente benéficas à formação do estudante, uma vez que tenham sido programadas de forma a considerar o nível acadêmico dos alunos e a prestar esclarecimento a respeito das características inerentes a cada um dos tipos de documentos. Não se trata de apresentar apenas "orientações gerais" sobre a produção de relatórios, por exemplo. Trata-se de discutir o relatório (quanto às seções que o integram, à linguagem científica que lhe é peculiar, à forma esperada de apresentação de ilustrações e tabelas etc) e de fazer uma análise crítica da produção dos alunos, confrontando-a em seguida com documentos de autoria de experts no assunto. Somente realizando ações dessa natureza, ensinaremos os alunos a "falar ciência" na perspectiva recomendada atualmente e que, segundo Lemke, ${ }^{30}$ inclui a compreensão dos padrões temáticos (definidos como padrões de relações semânticas que descrevem o conteúdo temático ou científico de uma área particular) e o uso da linguagem, segundo os padrões semânticos da Ciência, não simplesmente repetindo as pala- 
vras, mas construindo seus significados de acordo com o que é requerido em cada situação. A abordagem de questões éticas, relacionadas à comunicação científica, é também desejável. Essa abordagem favorece reflexões sobre aspectos que não são corriqueiramente vislumbrados pelos estudantes de graduação, principalmente nos primeiros anos do curso, e que pode promover um direcionamento mais adequado nas condutas que adotarão diante da comunicação científica. A inclusão, no âmbito da formação dos docentes de Química, de discussões acerca da comunicação científica é recomendável. Neste estudo, constatou-se que o professor reconhece a importância do domínio da comunicação em linguagem científica para a formação dos estudantes, mas nem sempre está seguro a respeito das orientações que deve oferecer sobre a forma mais adequada de produção de documentos científicos. Considerando a possibilidade de não ser esse um caso isolado, faz-se oportuna a abordagem de temas vinculados à comunicação científica em disciplinas pedagógicas aplicadas nos cursos de pós-graduação, uma vez que, em geral, os alunos de tais cursos serão futuros professores do ensino superior de Química.

\section{AGRADECIMENTOS}

Ao CNPq (Processo n $\left.{ }^{\circ} 306077 / 2006-0\right)$ pelo apoio financeiro e aos participantes da pesquisa, cujos nomes não serão citados por questões éticas.

\section{REFERÊNCIAS}

1. Meadows, A. J.; A Comunicação Científica, Briquet de Lemos Livros: Brasília, 1999.

2. http://info.scopus.com/detail/what/, acessada em Fevereiro 2007.

3. http://pubs.acs.org/journals/jacsat/promo/facts.pdf, acessada em Março 2007.

4. Gama, A. A. S.; Ferreira, V. F.; Quim. Nova 2004, 27, 687.

5. Gama, A. A. S.; Cadore, S.; Ferreira, V. F.; Quim. Nova 2003, 26, 681.

6. Queiroz, S. L.; Quim. Nova 2001, 24, 143; Leite, M. S. C. P.; Almeida, M. J. P. M.; Rev. Bras. Ens. Fis. 2001, 23, 458; Hunter, A. D.; J. Chem. Educ. 1998, 75, 1424; Ordman, A. B.; J. Chem. Educ. 1996, 73, 753.

7. Oliveira, J. R. S.; Queiroz, S. L.; Atas do V Encontro Nacional de Pesquisa em Ensino de Ciências, Bauru, Brasil, 2005.

8. ht t p : // s i stemas 1. us p.br: $8080 /$ ju piter w e b / obterDisciplina?sgldis=SQF0320\&verdis=1, acessada em Fevereiro 2007.

9. h t p : //s i stemas 1. us p.br: $8080 /$ ju piterweb/ obterDisciplina?sgldis=SQF0321\&verdis=1, acessada em Fevereiro 2007.

10. Brandão, C. R.; Repensando a Pesquisa Participante, $3^{\mathrm{a}}$ ed., Brasiliense: São Paulo, 1999.

11. http://www.teses.usp.br/teses/disponiveis/75/75132/tde-11042007-140232/ , acessada em Setembro 2007.

12. Oliveira, J. R. S.; Queiroz, S. L ; Comunicação e Linguagem Científica: guia para estudantes de Química, Editora Átomo: Campinas, 2007.
13. Filipecki, A.; Barros, S. S.; Elia, M. F.; Ciênc. \& Educ. 2006, 12, 199; Silveira, F. F.; Neves, M. M. B. J.; Psic.: Teor. e Pesq. 2006, 22, 79; Cavalcante, L. I. P.; Rev. Bras. Educ. 2003, 22, 14; Bravo, B. M.; Pesa, M. A.; Investigações em Ensino de Ciências 2002, 10, a3, disponível em http:/ /www.if.ufrgs.br/public/ensino/vol10/n3/v10_n3_a3.html, acessada em Março 2007.

14. Sant'Ana, I. M.; Psicologia em Estudo 2005, 10, 227.

15. Buchweitz, B.; Investigações em Ensino de Ciências 2001, 6, a2, disponível em http://www.if.ufrgs.br/public/ensino/vol6/n2/v6_n2_a2.htm, acessada em Março 2007.

16. Chamlian, H. C.; Cad. Pesq. 2003, 18, 41.

17. Le Boterf, G. Em Repensando a Pesquisa Participante; Brandão, C. R., ed.; Brasiliense: São Paulo, 1999, cap. 3.

18. Valle, E. R. M.; Enfoque 1988, 16, 20.

19. Thiollent, M.; Metodologia da Pesquisa-Ação, 12a.ed., Cortez: São Paulo, 2003.

20. Araújo, C.; Educ. e Pesq. 2001, 27, 141.

21. Fonseca, L. M. M.; Dissertação de Mestrado, Universidade de São Paulo, Brasil, 2002.

22. Oliveira, J. R. S.; Queiroz, S. L.; Revista Electrónica de Enseñanza de las Ciencias 2007, 6, 673.

23. Zanon, D. A. V.; Almeida, M. J. P. M.; Queiroz, S. L.; Revista Electrónica de Enseñanza de las Ciencias 2007, 6, 56.

24. Latour, B.; Woolgar, S.; A Vida de Laboratório: a produção dos fatos científicos, Editora Relume Dumará: Rio de Janeiro, 1997.

25. Santos, G. R.; Sá, L. P.; Queiroz, S. L.; Quim. Nova 2006, 29, 1121.

26. Santos, G. R.; Queiroz, S. L.; Ciência \& Educação 2007, 13, 193.

27. Campanario, J.M.; Enseñanza de las Ciencias 2004, 22, 365.

28. Fortner, R.W.; J. Coll. Sci. Teach. 1999, 28, 261.

29. Johnson, D. W.; Johnson, R. T.; Holubec, E. J.; Los Nuevos Círculos del Aprendizaje, Aique: Buenos Aires, 1999

30. Lemke, J. L.; Aprender a Hablar Ciencia, Paidós: Buenos Aires, 1997.

31. Cacciatore, K. L.; Sevian, H.; J. Chem. Educ. 2006, 83, 1039; Widstrand, C. G.; Nordell, K. J.; Ellis, A. B.; J. Chem. Educ. 2001, 8, 1044; Rudd II, J. A.; Greenbowe, T. J.; Hand, B.; J. Coll. Sci. Teach. 2001, 31, 230.

32. Luz Jr., G. E.; Sousa, S. A.; Moita, G. C; Moita Neto, J. M.; Quim. Nova 2004, 27, 164

33. Tilstra, L.; J. Chem. Educ. 2001, 78, 762.

34. Arroio, A.; Rodrigues Filho, U. P.; Silva, A. B. F.; Quim. Nova 2006, 29, 1387.

35. Sá, L. P.; Francisco, C. A.; Queiroz, S. L.; Quim. Nova 2007, 30, 731.

36. Meyer, G. M.; J. Chem. Educ. 2003, 80, 1175.

37. Grace, D. M.; Gilsdorf, J. W.; J. Accoun. Educ. 2004, 22, 165.

38. Benítez-Bribiesca, L.; Modiano-Esquenazi, M.; Arch. Med. Res. 2006, 37, 423; Lemos, A. A. B.; Ciênc. Infor. 2005, 34, 7; Petroianu, A.; Rev. Assoc. Med. Bras. 2002, 48, 60.

39. Cavalcanti, B. N.; Rode, S. M.; Pesq. Odont. Bras. 2003, 17, 65.

40. Rosenfeldt, F. L.; Dowling, J. T.; Pepe, S.; Fullerton, M. J.; Heart, Lung Circul. 2000, 9, 82.

41. Hermes-Lima, M.; Ciência Hoje 2005, 36, 76.

42. h t t p : / / w w w a g e n c i a. f a p e s p. b r / boletim_dentro.php?data\%5Bid_materia_boletim $\% 5 \mathrm{D}=6858$, acessada em Março 2007.

43. Mabrouk, P. A.; J. Chem. Educ. 2001, 78, 1628; Paulson, D. R.; J. Chem. Educ. 2001, 78, 1047.

44. Moody, A. E.; Freemann, R. G.; J. Chem. Educ. 1999, 76, 1224. 